\title{
The immune system as a foundation for immunologic therapy and hematologic malignancies: a historical perspective
}

\author{
Frédéric Baron \\ Research assistant, National Fund for Scientific Research, Belgium \\ Fred Hutchinson Cancer Research Center, and the University of Liège, Belgium \\ Rainer Storb* MD \\ Fred Hutchinson Cancer Research Center, II00 Fairview Ave N, DI-100, PO Box 19024, Seattle, \\ WA 98109-1024, USA, and the University of Washington, Seattle, USA
}

\begin{abstract}
In this review we aim to provide a historical overview of the immunotherapeutic approaches which have been developed for the treatment of hematological malignancies. After briefly summarizing the development of the theory of cancer immune surveillance, we describe how initial studies discovering the efficacy of the immune-mediated graft-versus-tumor effects after allogeneic hematopoietic cell transplantation led to new transplantation approaches (termed non-myeloablative transplantation) relying almost exclusively on graft-versus-tumor effects for tumor eradication. We then summarize important steps in the development of tumor vaccines and autologous adoptive immunotherapy in patients with hematological malignancies. Finally, we describe historical discoveries leading to the recent success with monoclonal antibodies as treatment for lymphomas, chronic lymphocytic leukemia, and acute myeloid leukemia.
\end{abstract}

Key words: hematopoietic cell transplantation; immunotherapy; graft-versus-tumor effects; monoclonal antibody.

The notion of immunologic surveillance was first hypothesized in 1909 by Paul Ehrlich who proposed that during fetal and post-fetal development aberrant cells occurred frequently, but were eliminated or remained latent due to control by the immune system. ${ }^{1,2}$ Fifty years later, Thomas and Burnet developed the 'immunologic surveillance' theory which proposed that, under normal circumstances, the immune system

* Corresponding author. Address: Fred Hutchinson Cancer Research Center, 1100 Fairview Ave N, DI-100, PO Box 19024, Seattle, WA 98109-1024, USA. Tel.: + I 206667 4875; Fax: + I 2066676124.

E-mail address: rstorb@fhcrc.org (R. Storb).

I52I-6926/\$ - see front matter (c) 2006 Elsevier Ltd. All rights reserved. 
destroyed cancer cells when they were still in the early stages of tumor formation, probably because tumor cells differed antigenically from normal cells. ${ }^{3-5}$ Among the arguments in favor of this theory at that time were (I) the increased incidence of both hematologic and solid tumors observed in thymectomized mice and patients with primary immunodeficiencies; (2) the increased incidence of neoplasia in patients given immunosuppressive therapy (for example after organ transplantation); and (3) the demonstration that mice could be immunized against syngeneic tumors induced by viruses or chemical carcinogens. ${ }^{6}$

Studies in recently characterized athymic nude mice in the 1970s seriously challenged the cancer immunosurveillance theory. ${ }^{2}$ Indeed, although it was evident that thymus-deficient mice had increased incidences of lymphoma and virally induced tumors, they were not more susceptible to spontaneous or chemically induced tumors. ${ }^{7}$ These observations led to a progressive loss of interest in the immunosurveillance theory. However, the theory was resurrected in the 1990s because of four key observations. ${ }^{8,9}$ First, interferon- $\gamma($ IFN- $\gamma$ ) was shown to prevent both chemically induced and spontaneous tumors. ${ }^{10}$ Second, mice lacking the perforin (perforin -/-) gene, and mice deficient for the recombination-activating gene I (RAG-I) or RAG-2 (leading to a complete lack of $T$ cells and $B$ cells without affecting non-lymphoid organs) were shown to develop chemically induced tumors more frequently than their wildtype counterparts. ${ }^{11,12}$ Third, further studies in mice demonstrated that both the innate (NK-cell) and adaptative (T-cell) immune systems could be implicated in immune surveillance, since mice deficient for NK cells, T cells, NK/T cells, IFN- $\gamma$ or interleukin 12 (ILI2) all had increased susceptibilities to tumors (reviewed by Dunn et al). ${ }^{8,9}$ Finally, it was proposed that the immune system not only protected hosts again tumor development, but also facilitated outgrowth of tumors with reduced immunogenicity (the tumor editing hypothesis, recently reviewed by Dunn et al).

Although documented in mice, the importance of cancer immune surveillance in humans for prevention of non-viral tumors has remained highly controversial. ${ }^{8,9} \mathrm{Nev}-$ ertheless, a significant role for cancer immune surveillance in humans has been suggested by epidemiological data showing increased incidences of both lymphoma and various carcinomas in solid-organ graft recipients given immunosuppressive therapy ${ }^{13}$ and in patients with acquired immune deficiency syndromes. ${ }^{14}$

In parallel with - and with no initial relation to - the immune surveillance theory, allogeneic hematopoietic cell transplantation (HCT) was introduced by Thomas et al and Mathé et al as potential treatment for patients with hematologic malignancies. ${ }^{15-17}$ While the aim of the procedure was initially to administer supra-lethal doses of irradiation with the hope of destroying all leukemic or abnormal cells ${ }^{16}$, it was recognized in the late 1970s that allogeneic immunocompetent cells transplanted with the stem cells mediated therapeutic anti-tumor effects which were independent of the

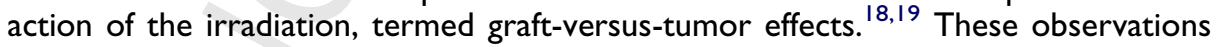
encouraged the study of new strategies of immune therapy for hematological malignancies via infusions of $T$ cells specific for tumor antigens, or via vaccination against leukemia-associated antigens (see the excellent review by Morris et al). ${ }^{20}$

In addition to the progress made with cellular-based immunotherapy, advances in the field of tumor-targeting monoclonal antibodies (mAbs) have taken place in recent years, as illustrated by the development of chimeric mAbs targeting the CD20 antigen, which are now used in all types of B-cell non-Hodgkin lymphomas (NHLs) ${ }^{21}$, or CD52 or CD33 antigens, used increasingly for the treatment of chronic lymphocytic leukemia $(C L L)^{22}$ or acute myeloid leukemia $(A M L)^{23,24}$ respectively. In addition, $\beta$-emitting radionuclides conjugated to mAb directed against the CD45 antigen (expressed on all 
hematopoietic cells) have been investigated as a way of increasing the anti-leukemic potency of conditioning regimens for HCT without inducing undue systemic toxicities. ${ }^{25,26}$

The aim of this chapter is to provide a brief historical overview of immunotherapeutic approaches developed to treat hematological malignancies. We have divided the chapter into three sections: (I) immunotherapy with allogeneic HCT; (2) autologous cell-based immunotherapy and vaccines; and (3) antibody-based therapies. However, these strategies are not independent from each other, as illustrated by recent studies combining mAbs with allogeneic $\mathrm{HCT}^{25-27}$

\section{IMMUNOTHERAPY WITH ALLOGENEIC HEMATOPOIETIC CELL TRANSPLANTATION}

\section{Demonstration of graft-versus-tumor effects in rodents and humans}

Several studies have demonstrated graft-versus-tumor effects in rodent models. In 1957 Barnes and Loutit first showed that mice with leukemia could not be cured by total body irradiation (TBI, 9.5 Gy) and infusion of syngeneic marrow, whereas mice given allogeneic marrow after the same dose of TBI survived for longer periods of time without evidence of leukemia, although eventually almost uniformly dying of graft-versus-host disease (GVHD). ${ }^{28}$ They proposed that a reaction of the donor marrow killed leukemic cells. This reaction was termed graft-versus-leukemia effect by $\mathrm{G}$. Mathe in $1965 .{ }^{17}$ Further studies showed that, while transplantation of $\mathrm{H}$-2-incompatible marrows caused GVHD and prevented leukemia relapses, transplantation of immunocompetent cells from syngeneic or from $\mathrm{H}$-2-identical murine donors did not cause GVHD, but did not produce detectable graft-versus-tumor effects either. ${ }^{29}$

The first evidence for graft-versus-tumor effects in humans came from a study published in 1979 showing a 2.5 -fold lower risk of leukemic relapse rates in allogeneic marrow recipients who developed acute GVHD in comparison with those who did not. ${ }^{18}$ However, this did not translate into improved progression-free survival, since acute GVHD was associated with increased non-relapse mortality. Two years later, the same authors observed that chronic GVHD, a disease mimicking autoimmune disorders and generally occurring late after HCT, was also associated with a reduced risk of leukemic relapse and improved progression-free survival in patients with advanced acute leukemia given allogeneic marrow grafts. ${ }^{19}$ Interestingly, the highest survival rate was observed in patients with chronic GVHD who did not have acute GVHD (de novo chronic GVHD, Figure I). The anti-leukemic effects of acute and chronic GVHD were confirmed in 1990 in a large study from the International Bone Marrow Transplant Registry (IBMTR). ${ }^{30}$ Further, patients given syngeneic marrow were shown to have increased risks of relapse in comparison to patients given allogeneic marrow who did not develop GVHD, demonstrating that graft-versus-tumor effects could be dissociated from clinically apparent GVHD. ${ }^{18,30}$ Finally, the important role of donor T cells in the graft-versus-tumor effect was highlighted by reports demonstrating that, although the incidence of GVHD was decreased following transplantation of T-celldepleted marrow, graft failure and leukemia relapse were significantly increased by this procedure. ${ }^{30-32}$

First attempts at increasing graft-versus-tumor effects in patients with high-risk leukemia by shortening the duration of post-grafting immunosuppression or by infusing donor buffy coats early after transplantation were not successful because of increased incidence of severe acute GVHD and increased non-relapse mortality. ${ }^{33}$ 


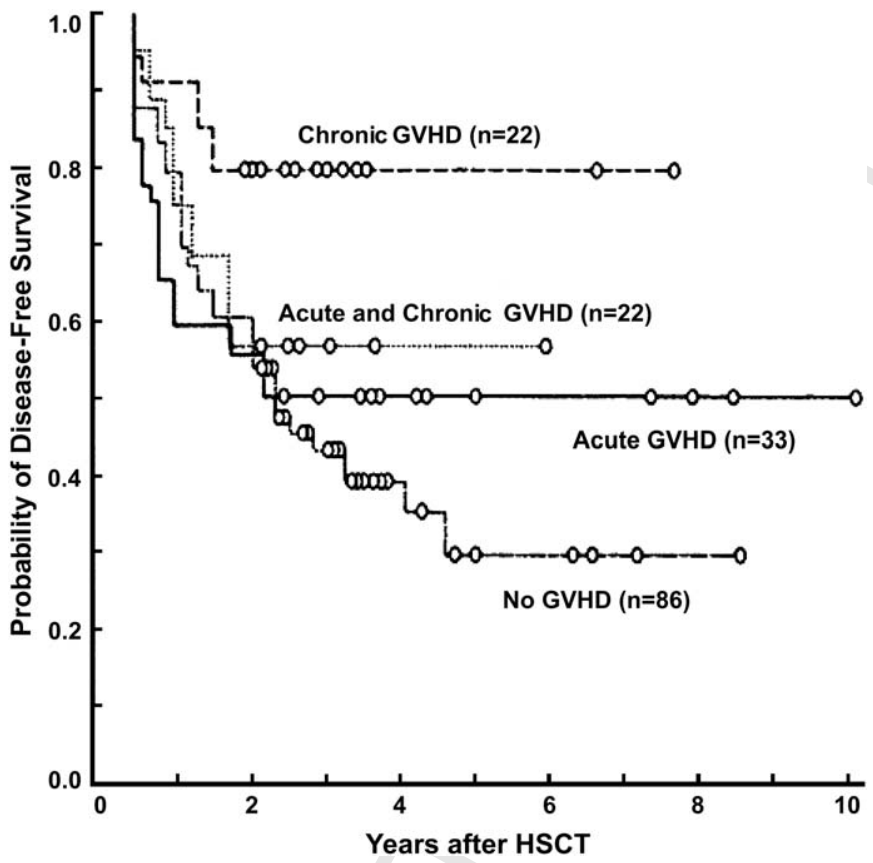

Figure I. Disease-free survivals of patients with hematological malignancies given cyclophosphamide and high-dose total body irradiation (TBI), HLA-matched related hematopoietic cell transplantation (HCT), and methotrexate (MTX) for prevention of graft-versus-host disease (GVHD). Data in patients with and without acute and chronic GVHD are shown. Modified from Weiden et al (198I, New England Journal of Medicine 304: 1529-1533) with permission.

\section{Donor lymphocytes infusion (DLI)}

Given the primary role of donor $\mathrm{T}$ cells in the graft-versus-tumor effect ${ }^{30-32}$ and the observation that patients who relapsed after transplantation occasionally achieved complete remission during flares of GVHD activity ${ }^{34}$, Kolb et $\mathrm{a}^{35}$ investigated the efficacy of donor lymphocyte infusions (DLI) in patients with leukemia relapse after allogeneic transplantation. The induction of durable complete remissions by DLI in a number of patients with either acute or chronic leukemia ${ }^{36,37}$, multiple myeloma ${ }^{38}$, or lymphomas ${ }^{39}$ demonstrated that graft-versus-tumor effects were capable of eradicating hematological malignancies, even in the absence of preceding chemotherapy.

Two large multicenter studies ${ }^{37,40}$ have analyzed outcomes after DLI in more than 400 patients with relapse after HCT. DLI induced sustained complete remissions in more than $60 \%$ of patients with chronic myeloid leukemia, and in $10-40 \%$ of patients with other hematologic malignancies. Acute GVHD and chronic GVHD were each associated with increased probabilities of disease responses ${ }^{40}$, although some patients achieved complete remissions without clinically evident GVHD., ${ }^{37,40}$

\section{Non-myeloablative and reduced-intensity conditioning}

Due to regimen-related toxicities, the use of conventional (myeloablative) allogeneic HCT has been restricted to younger and medically fit patients. ${ }^{1641-43}$ This is 
unfortunate since the median ages at diagnosis of patients with most hematological malignancies ranges from 65 to 70 years (Table I). Given the increasingly recognized importance of graft-versus-tumor effects for controlling cancer, several groups of investigators have explored allogeneic HCT after reduced-intensity or truly nonmyeloablative conditioning regimens ${ }^{44-49}$ in which some or all the burden of tumor eradication was shifted from high-dose chemoradiotherapy towards graft-versustumor effects. 50

On the basis of preclinical observations in a canine model of transplantation ${ }^{51}$, we have been investigating a very-low-intensity regimen combining low-dose TBI (2 Gy) with or without added fludarabine $\left(90 \mathrm{mg} / \mathrm{m}^{2}\right)$ and post-grafting immunosuppression with mycophenolate mofetil and cyclosporine. ${ }^{46,52,53}$ To date, more than 800 patients have been given allogeneic HCT after this non-myeloablative conditioning regimen on clinical trials carried out in several centers in the US and Europe, as described in the following paragraphs.

The regimen has been usually very well tolerated, and has been associated with fewer infections ${ }^{54}$ and less transplant-related toxicity ${ }^{55-61}$ than myeloablative conditioning, despite the fact that non-myeloablative conditioning was offered in older patients and those with medical comorbidities. Characteristics of the regimen included modest declines in peripheral-blood cell counts ${ }^{46,55}$, and gradual replacement of recipient hematopoiesis by donor-derived hematopoiesis. ${ }^{62,63}$ Acute GVHD of grades II, III and IV was seen in 33\%, $10 \%$ and $5 \%$ of patients given grafts from HLA-matched related donors (MRDs), compared with $41 \%, 9 \%$ and $3 \%$ in those given grafts from unrelated donors (URDs), respectively. ${ }^{64}$ Chronic GVHD occurred in $43 \%$ of MRD and in $45 \%$ of URD recipients. ${ }^{64}$ In comparison with patients given myeloablative conditioning, grade II-IV acute GVHD was significantly less frequent in non-myeloablative recipients, but the incidences of chronic GVHD were similar among patients given non-myeloablative or myeloablative conditioning. ${ }^{65}$

Table I. Median ages of patients at diagnoses and at hematopoietic cell transplantation (HCT) using myeloablative or non-myeloablative conditioning.

\begin{tabular}{|c|c|c|c|c|c|}
\hline \multirow[t]{3}{*}{ Disease } & \multicolumn{5}{|c|}{ Median ages of patients (years) } \\
\hline & \multicolumn{2}{|c|}{ Related donors } & \multicolumn{2}{|c|}{ Unrelated donors } & \multirow{2}{*}{$\begin{array}{l}\text { At diagnoses } \\
\text { (SEERS) }^{41}\end{array}$} \\
\hline & $\begin{array}{l}\text { Myeloablative } \\
\text { conditioning }^{\text {a }}\end{array}$ & $\begin{array}{l}\text { Non-myeloablative } \\
\text { conditioning }\end{array}$ & $\begin{array}{l}\text { Myeloablative } \\
\text { conditioning }^{\mathrm{a}}\end{array}$ & $\begin{array}{l}\text { Non-myeloablative } \\
\text { conditioning }^{\mathrm{b}}\end{array}$ & \\
\hline$\overline{C M L}$ & $40^{41}$ & $58^{70}$ & $36^{41}$ & $54^{71}$ & 67 \\
\hline AML & $28^{41}$ & $58^{73}$ & $33^{41}$ & $57^{73}$ & 68 \\
\hline $\mathrm{NHL}$ & $33^{41}$ & $53.5^{68}$ & $35^{41}$ & $53.5^{\mathrm{a} 68}$ & 65 \\
\hline MM & $45^{41}$ & $52^{67}$ & $45^{41}$ & $52^{106}$ & 70 \\
\hline CLL & $51^{41}$ & $55^{69}$ & $46^{41}$ & $58^{69}$ & 71 \\
\hline HD & $29^{41}$ & $37^{107}$ & $28^{41}$ & $37^{107}$ & 34 \\
\hline MDS & $40^{41}$ & $62^{73}$ & $4 I^{4 I}$ & $62^{73}$ & 68 \\
\hline Overall & $40^{41}$ & $55^{64}$ & $35^{41}$ & $55^{64}$ & - \\
\hline
\end{tabular}

SEERS, surveillance, epidemiology and end results; CML, chronic myeloid leukemia; AML, acute myeloid leukemia; NHL, non-Hodgkin lymphoma; MM, multiple myeloma; CLL, chronic lymphocytic leukemia; HD, Hodgkin disease; MDS, myelodysplastic syndrome.

${ }^{a}$ At the Fred Hutchinson Cancer Research Center (FHCRC).

${ }^{b}$ FHCRC consortium. 
Sustained tumor responses have been seen across all disease categories. ${ }^{66-72}$ Overall complete responses in patients with measurable disease at HCT approached $50 \%{ }^{50,64}$, while the remainder of the patients had partial responses or stable disease, or experienced disease progression or relapse. Chronic GVHD was associated with decreased relapse/progression $(P=0.006)$, and better progression-free survival $(P=$ $0.003) .{ }^{50}$ However, grades II and III/IV acute GVHD had no statistically significant impact on relapse/progression. Instead, acute GVHD was associated with increased non-relapse mortality. In agreement with what was observed after myeloablative conditioning ${ }^{19}$, the best progression-free survival was observed in patients with de novo chronic GVHD. ${ }^{50}$

We have recently reported on the efficacy of allogeneic HCT following nonmyeloablative conditioning in specific disease categories. Hegenbart et al summarized results of non-myeloablative HCT in 122 patients with acute myeloid leukemia, 117 of whom were ineligible for conventional HCT because of age and/or comorbidities. ${ }^{73}$ Median age at HCT was 58 (range 17-74) years. Two-year probabilities of overall survival were $5 \mathrm{I} \%$ for patients transplanted in first complete remission $(n=5 \mathrm{I}), 6 \mathrm{I} \%$ for those transplanted in second remission $(n=39)$, and $28 \%$ for those transplanted beyond second remission $(n=32)$. Kerbauy et al reported outcomes in 24 patients (median age 58 years) with chronic myeloid leukemia in the first chronic phase $(n=14)$ or beyond the first chronic phase $(n=10)$ given grafts from HLA-matched related donors. ${ }^{70}$ Most patients were deemed ineligible for conventional HCT either because of age $\geq 65$ years $(n=5)$, or because of comorbidities $(n=15)$. The 2 -year overall survival was $70 \%$ for patients transplanted in the first chronic phase and $56 \%$ for those with more advanced diseases. Most patients with sustained engraftment achieved molecular remissions (Figure 2). ${ }^{70,71}$ Scott et al compared efficacy of HCT after non-myeloablative $(n=38)$ versus myeloablative conditioning (busulfan and cyclophosphamide, $\mathrm{n}=\mathrm{I} \mid 2$ ) in patients over 40 years of age with myelodysplastic syndromes. ${ }^{72}$ In multivariate analyses, there were no significant differences in overall survival (HR $\mathrm{I} .2, P=0.56)$, progression-free survival (HR I.I, $P=0.60)$, and relapse risk (HR I.3, $P=0.43$ ) between the non-myeloablative versus myeloablative recipients, suggesting that graft-versus-tumor effects were more important than conditioning intensity in

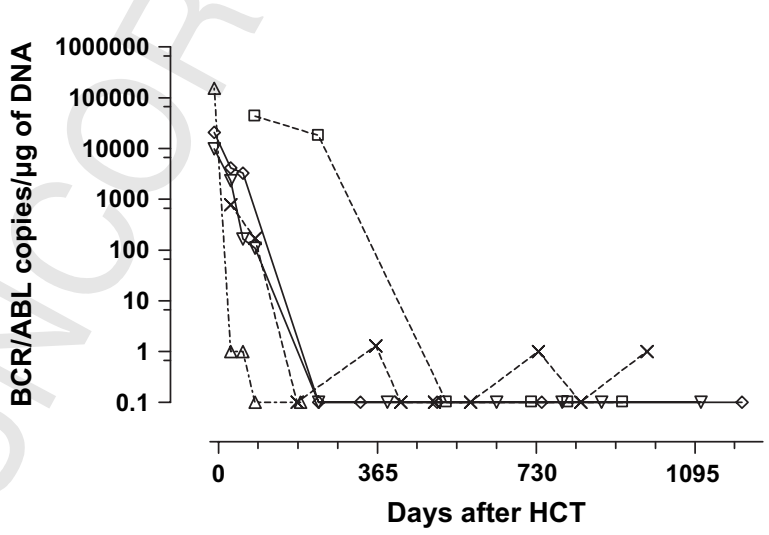

Figure 2. Evolution of $B C R / A B L$ mRNA in four patients with chronic myeloid leukemia (CML-CP\#I) and one patient with CML-AP given unrelated grafts after $2 \mathrm{~Gy}$ total body irradiation (TBI) and fludarabine. Molecular remissions were achieved 84-524 (median 230) days after hematopoietic cell transplantation (HCT). Reprinted from Baron et al (2005, Biology of Blood and Marrow Transplantation I I: 272-279) with permission. 
preventing relapse in patients with myelodysplastic syndromes. Results in 33 patients with mantle-cell lymphoma given grafts from related $(n=16)$ or unrelated $(n=17)$ donors were reported by Maris et al. ${ }^{68}$ Fourteen patients had failed high-dose autologous HCT. Of patients with measurable disease at HCT $(n=20), 85 \%$ achieved partial (10\%) or complete (75\%) remissions (Figure 3). Two-year incidences of relapse, non-relapse mortality, overall survival and progression-free survival were $9 \%, 24 \%$, $65 \%$, and $60 \%$, respectively. Finally, Sorror et al reported results of non-myeloablative allogeneic HCT in 64 patients with fludarabine-refractory chronic lymphocytic leukemia ${ }^{69}$; 44 patients received grafts from related donors, and 20 received grafts from unrelated donors. Of patients with measurable disease at HCT $(n=61), 67 \%$ achieved partial ( $17 \%)$ or complete (50\%) remissions. Two-year incidences of relapse, non-relapse

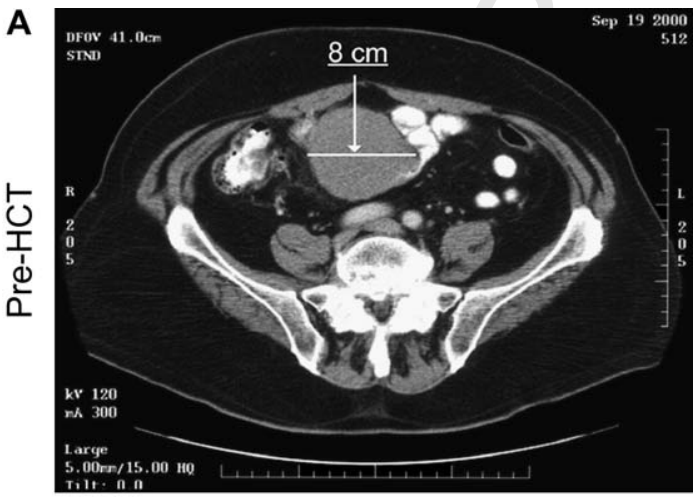

B

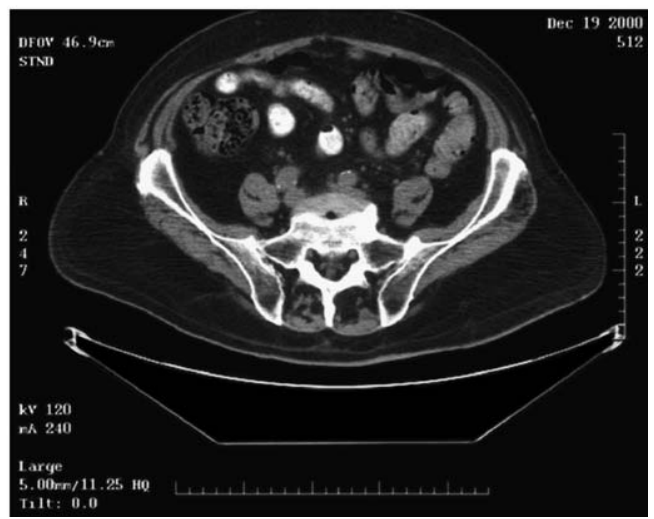

Figure 3. Example of graft-versus-tumor response in a patient with mantle-cell lymphoma treated with allogeneic hematopoietic cell transplantation (HCT) after non-myeloablative conditioning with fludarabine and low-dose (2 Gy) total body irradiation (TBI). At the time of allogeneic HCT the patient had recurrent disease following treatment with high-dose radiolabeled antibodies and autologous peripheral-blood stem-cell support. (A) Pretransplantation computed tomography (CT) scan image (day -27) through the upper pelvis demonstrating a mass $8 \mathrm{~cm} \times 7 \mathrm{~cm}$ extending through $120.5-\mathrm{cm}$ cuts. (B) CT scan image through the same region demonstrating complete resolution of the mass on day +74 after non-myeloablative transplantation from an HLA-matched unrelated donor. The patient has remained in remission 30 months after transplantation with no evidence of graft-versus-host disease (GVHD). From Maris et al (2004, Blood 104: 3535-3542) with permission. 
mortality, overall survival and progression-free survival were $18 \%, 22 \%, 60 \%$, and $52 \%$, respectively.

\section{NK cell alloreactivity: lessons from HLA-mismatched HCT}

In the late 1970s a subpopulation of lymphocytes - termed natural killer (NK) cells was described that could spontaneously kill (i.e. without previous immunization) a variety of target cell types, usually tumor cells or allogeneic hematopoietic cell lines. ${ }^{74}$ Those cells were believed to play a role in immunosurveillance against leukemias, genetic resistance to marrow allografts, and resistance to viral infections. ${ }^{74}$ However, although NK activity was found to be low in patients with leukemias, possibly as a result of the presence of blasts diluting or replacing NK cells, it was observed that NK function returned to normal by day 30 after allogeneic $\mathrm{HCT}$, and that NK function did not correlate with subsequent risk of relapse, suggesting that NK cells did not play a significant immunosurveillance role against leukemia after HLA-identical sibling HCT. ${ }^{75}$ Moreover, analyzing data from patients with aplastic anemia, there was no correlation between host NK-cell activity before HCT and the risk of graft rejection, suggesting that NK cells did not play a significant role in the graft rejection process after HLAidentical sibling $\mathrm{HCT}^{75}$ Subsequent observations in patients with severe combined immunodeficiency lacking T-cell function but having NK-cell function confirmed earlier canine studies $^{76,77}$ showing that NK cells were not involved in graft rejection of HLA-identical sibling marrows but played an important role in rejecting unrelated or MHC-haploidentical grafts. ${ }^{78}$

The identification of mechanisms regulating NK-cell activity in the mid 1990s renewed interest in NK cells. ${ }^{79}$ The activity of NK cells was regulated by a quantitative balance between inhibitory signals mediated by inhibitory killer immunoglobulin-like receptors (KIRs) and CD94/NKG2A, and by activating signals mediated by natural cytotoxicity receptors (NCRs), including recently identified NKG2D or DNAX accessory molecule-I (DNAM-I, CD226). ${ }^{79,80}$ The mechanisms of NK-cell inhibition were also identified. KIRs recognized allotypic determinants shared by different HLA-class I alleles: KIR2/DL2 and KIR2/DL3 recognized HLA-C group I alleles, KIR2/DLI recognized HLA-C group 2, and KIR3/DLI recognized HLA-Bw4 alleles. ${ }^{80}$ Conversely, CD94/NKG2A recognized overall expression of HLA class I molecules on target cells via the expression of HLA-E molecules on their surface. ${ }^{80}$ It was postulated that most tumor cells that lacked HLA class I molecules were promptly killed by NK cells because of the predominant effect of several activating receptors such as NKG2D or DNAX. It was also shown that the ligands for NK activating receptors were over-expressed on the surface of many tumor cells. ${ }^{81}$

These discoveries prompted Velardi et al to study the role of NK cells after HLAhaploidentical (donor and recipient pairs identical for one HLA haplotype but fully mismatched for the unshared haplotype) $\mathrm{HCT}^{82}$ The authors proposed that all mature NK cells expressed at least one inhibitory receptor for self-HLA, and thus that the presence or absence of functioning KIRs could be deduced by HLA-genotype. ${ }^{82}$ They then presented a simple algorithm in which comparisons between the donors' and recipients' HLA genotyping allowed prediction of NK alloreactivity (KIR ligand incompatibility model). Applying this model in patients given HLA-haploidentical HCT, they found that donor-versus-recipient NK-cell alloreactivity was associated with reduced risks of graft rejection, lower incidences of acute GVHD, and lower risks of relapse in patients with acute myeloid leukemia but not in acute lymphoblastic 
leukemia. $^{82}$ Several groups of investigators subsequently tested the KIR ligand incompatibility model in patients given grafts from HLA-mismatched unrelated donors. ${ }^{83-86}$ Two studies found lower risks of relapse in patients with KIR ligand incompatibility in the graft-versus-host direction, ${ }^{83,86}$ while two others did not find such associations. ${ }^{84,85}$

Given that HLA and KIR genes are on chromosomes 6 and 19, respectively, they are inherited independently. ${ }^{87}$ In addition, phenotyping of peripheral NK cells has demonstrated that the HLA genotype has only a subtle impact on KIR expression on peripheral NK cells. ${ }^{88,89}$ These observations were the basis for the 'missing KIR ligand model' in which donor-recipient NK-cell alloreactivity was predicted by analysis of donor KIR genotype and recipient HLA genotype. ${ }^{90,91}$ Because HLA and KIR segregate separately, the missing KIR ligand model could be applicable to HLA-identical HCT. Suggesting a potential role for NK cells in patients with acute myeloid leukemia given grafts from HLA-identical recipients, Hsu et al found a lower risk of relapse and better disease-free survival among patients who lacked the HLA ligand for one or more donor inhibitory KIR, in comparison to patients who had all of the HLA ligands. ${ }^{92}$

\section{AUTOLOGOUS CELLULAR-BASED IMMUNOTHERAPY AND VACCINES}

The concept of using autologous adoptive immunotherapy or cancer vaccine has had a long history of success in rodent models, but until now these successes have not been fully translated in humans. However, the discoveries of potential tumor-associated antigens and advances in tumor immunology have opened the way for the development of more effective strategies.

\section{Tumor-associated antigens and transfer of tumor-specific $\mathbf{T}$ cells}

The existence of tumor-specific antigens was first demonstrated in the 1950s by studies showing that mice could be immunized against syngeneic tumors induced by chemical carcinogens or oncoviruses. ${ }^{4}$ While the lower incidences of relapse after allogeneic $\mathrm{HCT}$ compared with syngeneic $\mathrm{HCT}^{30}$ demonstrated the importance of T-cell responses to minor histocompatibility antigens as targets of graft-versus-tumor effects, other types of protein exclusively expressed by tumor cells - such as the immunoglobulin idiotype (Ig-Id) in B-cell lymphoma or multiple myeloma, bcr/abl protein in chronic myeloid leukemia (CML), or Epstein-Barr-virus- (EBV-) associated proteins in Hodgkin disease or Burkitt's lymphoma - or protein over-expressed by tumor cells (such as proteinase-3, or WT-I), were thought to also play roles in graft-versus-tumor effects. For example, Molldrem et al observed a strong correlation between T-cell responses directed against proteinase 3 and clinical responses of chronic myeloid leukemia cells to interferon- $\gamma$ or allogeneic HCT. $^{93}$

By optimizing culture conditions it became possible to isolate from normal donors or from leukemia patients infrequent $T$ cells which had cytotoxic activity against such tumor-associated antigens both in vitro and in xenotransplantation models. ${ }^{20,94}$ Studies in the early 1990s showed that it was possible to restore T-cell immunity to cytomegalovirus (CMV) after allogeneic HCT by transfer of CMV-specific T cells. ${ }^{95}$ Similar results were obtained with EBV as target. ${ }^{96}$ However, generating sufficient numbers of tumor-specific $T$ cells with a high affinity against patient-specific tumor-associated 
antigen, and assuring their persistence after injection, have remained challenging. ${ }^{20}$ These limitations might be overcome by recent approaches that have used genetic modifications of $T$ cells, for example by transfer of genes coding for tumor-specific T-cell receptors with or without genes coding for signaling domains of co-stimulatory molecules (see excellent reviews by Morris et al and Rossig and Brenner). ${ }^{20,97}$

\section{Vaccination}

A recent review of vaccination trials performed in over 400 patients with solid cancer (mainly metastatic melanomas) showed an objective response rate of only $2.6 \% .{ }^{98}$ However, more encouraging results have been observed in patients with non-Hodgkin B-cell lymphoma $(\mathrm{NHL})$ by targeting the tumor-specific Ig-ld, with $20-35 \%$ of patients achieving objective responses. 21,99

B-cell NHL has been an ideal target for tumor vaccines because malignant B cells express both co-stimulatory molecules and a highly immunogenic target antigen (the Ig-ld).$^{98}$ Early observations in 1982 provided proof of principle that the immune system was able to target Ig-ld and kill Ig-ld-positive (lymphoma) cells, since mAbs directed against the Ig-ld induced tumor regression and even sustained clinical remissions in a subset of patients with $\mathrm{NHL} .{ }^{100}$ However, in a number of patients tumors recurred which originated from cells that contained mutations of the unique IgId antigen that was recognized by the mAbs. ${ }^{99}$ This prompted investigations of specific Ig-Id vaccination in the early 1990s. Researchers at Stanford University pioneered this strategy, and used Ig-Id conjugated to the carrier protein keyhole limpet hemocyanin $(\mathrm{KLH})$, and an adjuvant (Syntax adjuvant formulation). This strategy led to polyclonalantibody and T-cell responses directed against several Ig-Id epitopes and resulted in a decreased risk of tumor escape. ${ }^{99}$ Other investigators added injection of granulocyte-macrophage-colony-stimulating factor (GM-CSF) in order to promote immune responses. ${ }^{21}$ Results of phase-Il studies in patients with follicular NHL who were in complete remission at the beginning of the trial suggested effectiveness of the vaccine in promoting anti Ig-Id immunity and clinical efficacy. This has led to the development of phase-III clinical trials. Similarly, Ig-Id immunization has led to anti-idiotype immunity in patients with multiple myeloma, although apparently this has as yet not translated into improved survival. ${ }^{101}$

One strategy to increase antigen presentation has consisted of first pulsing maturing dendritic cells in vitro and then administering the cells, followed by Ig-ld protein boosts. This has resulted in objective responses in $20-35 \%$ of patients with B-cell $\mathrm{NHL}$ who had measurable disease at the time of the vaccination. ${ }^{02}$

Ongoing studies are testing efficacy of vaccines directed against other tumorassociated antigens, such as BCR/ABL protein or proteinase $3 .{ }^{24}$

Another approach involved injecting autologous or allogeneic tumor cells that were genetically modified to secrete cytokines (such as GM-CSF) locally. This might allow generation of immunity against several tumor-selective antigens (polyvalent vaccination), thereby reducing the risk of antigen escape of tumor cells. ${ }^{24}$

\section{MONOCLONAL ANTIBODIES}

The development of murine and rat hybridoma technologies in the 1970s has allowed the production of mAbs of predefined specificity. ${ }^{103}$ Despite the relative success with anti- mAbs directed against Ig-Id (see above) ${ }^{100}$, most rodent mAbs directed against 
human myeloid, B-cell or T-cell antigens have failed to produce significant responses in vivo. ${ }^{104}$ These studies also revealed the deleterious effects of human anti-mouse antibodies (HAMA). ${ }^{104}$ In 1994, it was shown that adding the human IgGI Fc region to murine $\mathrm{mAb}$ allowed more efficient complement-dependent cytotoxicity (CDC) and increased antibody-dependent cellular cytotoxicity (ADCC) in comparison with the murine $\mathrm{Fc}$ region. ${ }^{105}$ The use of human chimeric mAb has decreased host anti-mAb responses, and increased the mAbs' serum half-lives. ${ }^{105}$

Another important consideration for the efficacy of mAbs has been the characteristics of the target antigens. Ideal antigens should be expressed at high density on the tumor cells (>10000 binding sites per cell) and be weakly expressed by normal cells. ${ }^{104}$

Two different groups of humanized mAbs have been developed. The first group of mAbs has targeted antigens (such as CD20, CD45 or CD52) that were slowly or minimally internalized after binding and relied on extracellular mechanisms of cytotoxicity such as $C D C$ or ADCC, or on being conjugated with $\beta$-emitting radionuclides. Examples of humanized antibodies directed against such targets currently in clinical use include rituximab (anti-CD20) ${ }^{21}$ and alemtuzumab (anti-CD52). ${ }^{22}$ An example of a radiolabeled $\mathrm{mAb}$ is a ${ }^{|3|} \mid$-anti-CD45 antibody used before allogeneic $\mathrm{HCT}^{25}$

The second group of mAbs was directed at target antigens that are internalized after binding, such as CD33. Internalization has been required for those mAbs that were developed for delivering toxins or chemotherapeutic drugs into the cytoplasm of tumor cells. An example of a humanized $\mathrm{mAb}$ in clinical use is gemtuzumab ozogamicin, a mAb that targets $C D 33$ and is conjugated with calicheamicin, a highly potent antitumor antibiotic that cleaves double-stranded DNA at specific sequences. ${ }^{23}$

\section{SUMMARY}

During the past 50 years, the use of the immune system to destroy hematological malignancies has moved from a hypothesis to an effective therapy for thousands of patients. Efficacy of immunotherapy has been demonstrated in patients with hematological malignancies undergoing allogeneic HCT following non-myeloablative conditioning. Independent from advances in allogeneic HCT, MAbs targeting CD20, CD52, CD45 or CD33 have been developed and become important therapeutic tools for B-cell NHL, chronic lymphocytic leukemia, and acute myeloid leukemia. Finally, recent progress in tumor immunology might lead to successful tumor vaccines and to the development of highly cytotoxic autologous tumor-specific T cells.

\section{Practice points}

- allogeneic immunocompetent cells transplanted with the graft mediate therapeutic anti-tumor effects after allogeneic HCT (graft-versus-tumor effect)

- efficacy of graft-versus-tumor effect has been demonstrated in patients with hematological malignancies undergoing allogeneic HCT following nonmyeloablative conditioning

- monoclonal antibodies targeting CD20, CD52, CD45 or CD33 have been developed and become important therapeutic tools for the treatment of $B$-cell non-Hodgkin lymphoma, chronic lymphocytic leukemia, and acute myeloid leukemia 
- combination of HCT following non-myeloablative conditioning with monoclonal antibodies in order to increase their anti-tumor efficacy

- further description of mechanisms by which NK cells might eradicate hematological malignancies

- genetic modification of tumor-specific cytotoxic T cells in order to increase their efficacy

\section{ACKNOWLEDGEMENTS}

This work was supported by grants CA78902, CAI8029, CAI5704, DK427I6, and HL36444 of the National Institutes of Health, Bethesda, MD, USA. Frédéric Baron is research assistant of the National Fund for Scientific Research (FNRS) Belgium and supported in part by postdoctoral grants from the Fulbright Commission.

\section{REFERENCES}

I. Ehrlich P. Ueber den jetzigen stand der Karzinomforschung. Nederlands Tijdschrift voor Geneeskunde 1909; 5: 273-290.

2. Schwartz RS. Another look at immunologic surveillance (Review). The New England Journal of Medicine 1975; 293(4): |8I-184.

3. Burnet M. The Clonal Selection Theory of Acquired Immunity. London: Cambridge University Press, 1959.

4. Burnet FM. The concept of immunological surveillance (Review). Progress in Experimental Tumor Research 1970; 13: 1-27.

5. Thomas L. On immunosurveillance in human cancer. Yale Journal of Biology \& Medicine 1982; 55(3-4): 329-333.

6. Wilson DB. Immunological surveillance. Science 1970; 169(949): 1006-10II.

7. Stutman $\mathrm{O}$. Chemical carcinogenesis in nude mice: comparison between nude mice from homozygous matings and heterozygous matings and effect of age and carcinogen dose. Journal of the National Cancer Institute 1979; 62(2): 353-358.

8. Dunn GP, Bruce AT, lkeda $\mathrm{H}$ et al. Cancer immunoediting: from immunosurveillance to tumor escape (Review). Nature Immunology 2002; 3(I I): 99I-998.

9. Dunn GP, Old LJ \& Schreiber RD. The immunobiology of cancer immunosurveillance and immunoediting (Review). Immunity 2004; 2 I (2): I37-I48.

10. Kaplan DH, Shankaran V, Dighe AS et al. Demonstration of an interferon gamma-dependent tumor surveillance system in immunocompetent mice. Proceedings of the National Academy of Sciences of the United States of America 1998; 95(I3): 7556-756I.

II. Smyth MJ, Thia KY, Street SE et al. Perforin-mediated cytotoxicity is critical for surveillance of spontaneous lymphoma. The Journal of Experimental Medicine 2000; 192(5): 755-760.

12. Shankaran V, Ikeda $H$, Bruce AT et al. IFNgamma and lymphocytes prevent primary tumour development and shape tumour immunogenicity. Nature 200 I; 410(6832): II07-IIII.

13. Birkeland SA, Storm HH, Lamm LU et al. Cancer risk after renal transplantation in the Nordic countries, 1964-1986. International Journal of Cancer 1995; 60(2): 183-189.

14. Engels EA \& Goedert JJ. Human immunodeficiency virus/acquired immunodeficiency syndrome and cancer: past, present, and future. Journal of the National Cancer Institute 2005; 97(6): 407-409.

15. Thomas ED, Lochte Jr. HL, Lu WC et al. Intravenous infusion of bone marrow in patients receiving radiation and chemotherapy. The New England Journal of Medicine 1957; 257: 49I-496. 
16. Little M-T \& Storb R. History of haematopoietic stem-cell transplantation. Nature Reviews Cancer 2002; 2: $23 \mathrm{I}-238$.

17. Mathe G, Amiel JL, Schwarzenberg L et al. Adoptive immunotherapy of acute leukemia: experimental and clinical results. Cancer Research 1965; 25(9): I525-I53I.

18. Weiden PL, Flournoy N, Thomas ED et al. Antileukemic effect of graft-versus-host disease in human recipients of allogeneic-marrow grafts. The New England Journal of Medicine 1979; 300: 1068-1073.

19. Weiden PL, Sullivan KM, Flournoy $\mathrm{N}$ et al. Antileukemic effect of chronic graft-versus-host disease. Contribution to improved survival after allogeneic marrow transplantation. The New England Journal of Medicine 198I; 304: 1529-I533.

20. Morris E, Hart D, Gao L et al. Generation of tumor-specific T-cell therapies. Blood Reviews 2006; 20: 6I-69.

21. Maloney DG. Immunotherapy for non-Hodgkin's lymphoma: monoclonal antibodies and vaccines (Review). Journal of Clinical Oncology 2005; 23(26): 642I-6428.

22. Keating MJ, Flinn I, Jain V et al. Therapeutic role of alemtuzumab (Campath- $I H)$ in patients who have failed fludarabine: results of a large international study. Blood 2002; 99(10): 3554-356I.

23. Sievers EL, Larson RA, Stadmauer EA et al. Efficacy and safety of gemtuzumab ozogamicin in patients with CD33-positive acute myeloid leukemia in first relapse. Journal of Clinical Oncology 200 I; 19(13): 3244-3254.

24. Caligiuri MA, Velardi A, Scheinberg DA et al. Immunotherapeutic approaches for hematologic malignancies (Review). Hematology 2004: 337-353.

25. Pagel JM, Matthews DC, Appelbaum FR et al. The use of radioimmunoconjugates in stem cell transplantation (Mini-review). Bone Marrow Transplantation 2002; 29: 807-816.

26. Pagel JM, Appelbaum FR, Gooley T et al. ${ }^{13 \mid}$ I-anti-CD45 antibody plus busulfan and cyclophosphamide before allogeneic hematopoietic cell transplantation for treatment of acute myeloid leukemia in first remission. Blood 2006; 107: 2184-2191.

27. Khouri IF, Lee MS, Saliba RM et al. Nonablative allogeneic stem cell transplantation for chronic lymphocytic leukemia: impact of rituximab on immunomodulation and survival. Experimental Hematology 2004; 32(I): 28-35.

28. Barnes DWH \& Loutit JF. Treatment of murine leukaemia with $\mathrm{x}$-rays and homologous bone marrow: II. British Journal of Haematology 1957; 3: 24I-252.

29. Bortin MM, Rimm AA, Rose WC et al. Graft-versus-leukemia. V. Absence of antileukemic effect using allogeneic H-2-identical immunocompetent cells. Transplantation 1974; I 8: 280-283.

30. Horowitz MM, Gale RP, Sondel PM et al. Graft-versus-leukemia reactions after bone marrow transplantation. Blood 1990; 75: 555-562.

31. Martin PJ, Hansen JA, Buckner CD et al. Effects of in vitro depletion of T cells in HLA-identical allogeneic marrow grafts. Blood 1985; 66: 664-672.

32. Maraninchi D, Gluckman E, Blaise D et al. Impact of T-cell depletion on outcome of allogeneic bonemarrow transplantation for standard-risk leukaemias. Lancet 1987; 2: 175-178.

33. Sullivan KM, Storb R, Buckner CD et al. Graft-versus-host disease as adoptive immunotherapy in patients with advanced hematologic neoplasms. The New England Journal of Medicine 1989; 320: 828-834.

34. Sullivan KM, Weiden PL, Storb $R$ et al. Influence of acute and chronic graft-versus-host disease on relapse and survival after bone marrow transplantation from HLA-identical siblings as treatment of acute and chronic leukemia. Blood 1989; 73: 1720-1728.

35. Kolb HJ, Mittermüller J, Clemm Ch et al. Donor leukocyte transfusions for treatment of recurrent chronic myelogenous leukemia in marrow transplant patients. Blood 1990; 76: 2462-2465.

36. Kolb HJ, Schattenberg A, Goldman JM et al. Graft-versus-leukemia effect of donor lymphocyte transfusions in marrow grafted patients. European Group for Blood and Marrow Transplantation Working Party Chronic Leukemia. Blood 1995; 86(5): 204I-2050.

37. Collins Jr. RH, Shpilberg O, Drobyski WR et al. Donor leukocyte infusions in 140 patients with relapsed malignancy after allogeneic bone marrow transplantation. Journal of Clinical Oncology 1997; I 5(2): 433-444.

38. Lokhorst HM, Schattenberg A, Cornelissen JJ et al. Donor lymphocyte infusions for relapsed multiple myeloma after allogeneic stem-cell transplantation: predictive factors for response and long-term outcome. Journal of Clinical Oncology 2000; 18(16): 303I-3037.

39. Peggs KS, Mackinnon S \& Linch DC. The role of allogeneic transplantation in non-Hodgkin's lymphoma. British Journal of Haematology 2005; I 28(2): I53-I68. 
40. Kolb HJ, Schmidt C, Barrett AJ et al. Graft-versus-leukemia reactions in allogeneic chimeras. Blood 2004; I03(3): 767-776.

4I. Storb R. Allogeneic hematopoietic stem cell transplantation - yesterday, today, and tomorrow. Experimental Hematology 2003; 3 I: I-I0.

42. Baron F \& Storb R. Allogeneic hematopoietic cell transplantation as treatment for hematological malignancies: a review. Springer Seminars in Immunopathology 2004; 26: 71-94.

43. Baron F \& Storb R. Allogeneic hematopoietic cell transplantation following nonmyeloablative conditioning as treatment for hematologic malignancies and inherited blood disorders (Review). Molecular Therapy 2006; 13(I): 26-4I.

44. Giralt S, Estey E, Albitar M et al. Engraftment of allogeneic hematopoietic progenitor cells with purine analog-containing chemotherapy: harnessing graft-versus-leukemia without myeloablative therapy. Blood 1997; 89(12): 453I-4536.

45. Slavin S, Nagler A, Naparstek E et al. Nonmyeloablative stem cell transplantation and cell therapy as an alternative to conventional bone marrow transplantation with lethal cytoreduction for the treatment of malignant and nonmalignant hematologic diseases. Blood 1998; 9I(3): 756-763.

46. McSweeney PA, Niederwieser D, Shizuru JA et al. Hematopoietic cell transplantation in older patients with hematologic malignancies: replacing high-dose cytotoxic therapy with graft-versus-tumor effects. Blood 200I; 97(II): 3390-3400.

47. Childs R, Chernoff $A$, Contentin $N$ et al. Regression of metastatic renal-cell carcinoma after nonmyeloablative allogeneic peripheral-blood stem-cell transplantation. The New England Journal of Medicine 2000; 343(II): 750-758.

48. Morris E, Thomson K, Craddock $\mathrm{C}$ et al. Outcomes after alemtuzumab-containing reduced-intensity allogeneic transplantation regimen for relapsed and refractory non-Hodgkin lymphoma. Blood 2004; I04(I3): 3865-387I.

49. Mohty $M$, de Lavallade $H$, Ladaique $P$ et al. The role of reduced intensity conditioning allogeneic stem cell transplantation in patients with acute myeloid leukemia: a donor vs no donor comparison. Leukemia 2005; 19(6): 916-920.

50. Baron F, Maris MB, Sandmaier BM et al. Graft-versus-tumor effects after allogeneic hematopoietic cell transplantation with nonmyeloablative conditioning. Journal of Clinical Oncology 2005; 23(9): 1993-2003.

5I. Storb R, Yu C, Wagner JL et al. Stable mixed hematopoietic chimerism in DLA-identical littermate dogs given sublethal total body irradiation before and pharmacological immunosuppression after marrow transplantation. Blood 1997; 89(8): 3048-3054.

52. Niederwieser D, Maris M, Shizuru JA et al. Low-dose total body irradiation (TBI) and fludarabine followed by hematopoietic cell transplantation (HCT) from HLA-matched or mismatched unrelated donors and postgrafting immunosuppression with cyclosporine and mycophenolate mofetil (MMF) can induce durable complete chimerism and sustained remissions in patients with hematological diseases. Blood 2003; 101 (4): 1620-1629.

53. Maris MB, Niederwieser D, Sandmaier BM et al. HLA-matched unrelated donor hematopoietic cell transplantation after nonmyeloablative conditioning for patients with hematologic malignancies. Blood 2003; 102(6): 2021-2030.

54. Junghanss C, Marr KA, Carter RA et al. Incidence and outcome of bacterial and fungal infections following nonmyeloablative compared with myeloablative allogeneic hematopoietic stem cell transplantation: a matched control study. Biology of Blood and Marrow Transplantation 2002; 8: 5I2-520.

55. Weissinger F, Sandmaier BM, Maloney DG et al. Decreased transfusion requirements for patients receiving nonmyeloablative compared with conventional peripheral blood stem cell transplants from HLA-identical siblings. Blood 200 I; 98(I3): 3584-3588.

56. Hogan WJ, Maris M, Storer B et al. Hepatic injury after nonmyeloablative conditioning followed by allogeneic hematopoietic cell transplantation: a study of 193 patients. Blood 2004; 103(I): 78-84.

57. Fukuda T, Hackman RC, Guthrie KA et al. Risks and outcomes of idiopathic pneumonia syndrome after nonmyeloablative and conventional conditioning regimens for allogeneic hematopoietic stem cell transplantation. Blood 2003; 102(8): 2777-2785.

58. Sorror ML, Maris MB, Storer B et al. Comparing morbidity and mortality of HLA-matched unrelated donor hematopoietic cell transplantation after nonmyeloablative and myeloablative conditioning: influence of pretransplant comorbidities. Blood 2004; 104(4): 96I-968. 
59. Diaconescu R, Flowers CR, Storer B et al. Morbidity and mortality with nonmyeloablative compared to myeloablative conditioning before hematopoietic cell transplantation from HLA matched related donors. Blood 2004; 104(5): I550-1558.

60. Parikh CR, Schrier RW, Storer B et al. Comparison of ARF after myeloablative and nonmyeloablative hematopoietic cell transplantation. American Journal of Kidney Diseases 2005; 45(3): 502-509.

6I. Chien JW, Maris MB, Sandmaier BM et al. Comparison of lung function after myeloablative and 2 Gy of total body irradiation-based regimens for hematopoietic stem cell transplantation. Biology of Blood and Marrow Transplantation 2005; I I: 288-296.

62. Baron F, Baker JE, Storb R et al. Kinetics of engraftment in patients with hematologic malignancies given allogeneic hematopoietic cell transplantation after nonmyeloablative conditioning. Blood 2004; 104(8): 2254-2262.

63. Baron F, Maris MB, Storer BE et al. High doses of transplanted CD34+ cells are associated with rapid T-cell engraftment and lessened risk of graft rejection, but not more graft-versus-host disease after nonmyeloablative conditioning and unrelated hematopoietic cell transplantation. Leukemia 2005; 19: 822-828.

64. Sandmaier BM, Maris M, Maloney DG et al. Low-dose total body irradiation (TBI) conditioning for hematopoietic cell transplants (HCT) from HLA-matched related (MRD) and unrelated (URD) donors for patients with hematologic malignancies: a five-year experience [Abstract]. Blood 2003; 102 (Part I): (I I)78a-9a, \#264.

65. Mielcarek M, Martin PJ, Leisenring $W$ et al. Graft-versus-host disease after nonmyeloablative versus conventional hematopoietic stem cell transplantation. Blood 2003; I02(2): 756-762.

66. Feinstein LC, Sandmaier BM, Hegenbart $U$ et al. Non-myeloablative allografting from human leucocyte antigen-identical sibling donors for treatment of acute myeloid leukaemia in first complete remission. British Journal of Haematology 2003; I 20(2): 28I-288.

67. Maloney DG, Molina AJ, Sahebi F et al. Allografting with nonmyeloablative conditioning following cytoreductive autografts for the treatment of patients with multiple myeloma. Blood 2003; 102(9): 3447-3454.

68. Maris MB, Sandmaier BM, Storer BE et al. Allogeneic hematopoietic cell transplantation after fludarabine and $2 \mathrm{~Gy}$ total body irradiation for relapsed and refractory mantle cell lymphoma. Blood 2004; 104(I2): 3535-3542.

69. Sorror ML, Maris MB, Sandmaier BM et al. Hematopoietic cell transplantation after nonmyeloablative conditioning for advanced chronic lymphocytic leukemia. Journal of Clinical Oncology 2005; 23(16): 3819-3829.

70. Kerbauy FR, Storb R, Hegenbart $U$ et al. Hematopoietic cell transplantation from HLA-identical sibling donors after low-dose radiation-based conditioning for treatment of CML. Leukemia 2005; 19: 990-997.

7I. Baron F, Maris MB, Storer BE et al. HLA-matched unrelated donor hematopoietic cell transplantation after nonmyeloablative conditioning for patients with chronic myeloid leukemia. Biology of Blood and Marrow Transplantation 2005; I I: 272-279.

72. Scott BL, Sandmaier BM, Storer B et al. Myeloablative vs nonmyeloablative allogeneic transplantation for patients with myelodysplastic syndrome or acute myelogenous leukemia with multilineage dysplasia: a retrospective analysis. Leukemia 2006; 20: 128-135.

73. Hegenbart U, Niederwieser D, Sandmaier BM et al. Treatment for acute myelogenous leukemia (AML) by low dose total body irradiation (TBI) based conditioning and hematopoietic cell transplantation (HCT) from related and unrelated donors. Journal of Clinical Oncology 2006; 24: 444-453.

74. Herberman RB, Djeu J, Kay HD et al. Natural killer cells: characteristics and regulation of activity. Immunological Reviews 1979; 44: 43-70.

75. Livnat S, Seigneuret M, Storb R et al. Analysis of cytotoxic effector cell function in patients with leukemia or aplastic anemia before and after marrow transplantation. Journal of Immunology 1980; I 24: 48I-490.

76. Raff RF, Loughran Jr. TP, Deeg HJ et al. Role of radiation-resistant large granular lymphocytes in the rejection of unrelated DLA-nonidentical marrow grafts in dogs. Transplantation Proceedings 1987; 19: 2718-2720.

77. Raff RF, Sandmaier BM, Graham T et al. 'Resistance' to DLA-nonidentical canine unrelated marrow grafts is unrestricted by the major histocompatibility complex. Experimental Hematology 1994; 22: 893-897. 
16 F. Baron and R. Storb

78. Fischer A, Le Deist F, Hacein-Bey-Abina S et al. Severe combined immunodeficiency. A model disease for molecular immunology and therapy (Review). Immunological Reviews 2005; 203: 98-109.

79. Moretta A, Bottino C, Vitale M et al. Receptors for HLA class-I molecules in human natural killer cells (Review). Annual Review of Immunology 1996; 14: 619-648.

80. Moretta L, Bottino C, Pende D et al. Different checkpoints in human NK-cell activation (Review). Trends in Immunology 2004; 25(12): 670-676.

8I. Groh V, Wu J, Yee C et al. Tumour-derived soluble MIC ligands impair expression of NKG2D and T-cell activation. Nature 2002; 419(6908): 734-738.

82. Ruggeri L, Capanni M, Urbani E et al. Effectiveness of donor natural killer cell alloreactivity in mismatched hematopoietic transplants. Science 2002; 295(5562): 2097-2100.

83. Giebel S, Locatelli F, Lamparelli T et al. Survival advantage with KIR ligand incompatibility in hematopoietic stem cell transplantation from unrelated donors. Blood 2003; 102(3): 814-819.

84. Davies SM, Ruggieri L, DeFor T et al. Evaluation of KIR ligand incompatibility in mismatched unrelated donor hematopoietic transplants. Killer immunoglobulin-like receptor. Blood 2002; I 00(I0): 3825-3827.

85. Bornhauser M, Schwerdtfeger R, Martin H et al. Role of KIR ligand incompatibility in hematopoietic stem cell transplantation using unrelated donors. Blood 2004; I03(7): 2860-286I.

86. Beelen DW, Ottinger HD, Ferencik $S$ et al. Genotypic inhibitory killer immunoglobulin-like receptor ligand incompatibility enhances the long-term antileukemic effect of unmodified allogeneic hematopoietic stem cell transplantation in patients with myeloid leukemias. Blood 2005; 105(6): 2594-2600.

87. Parham P \& McQueen KL. Alloreactive killer cells: hindrance and help for haematopoietic transplants (Review). Nature Reviews Immunology 2003; 3(2): 108-I22.

88. Frohn C, Schlenke $P$ \& Kirchner $H$. The repertoire of HLA-Cw-specific NK cell receptors CDI58 a/b (EB6 and GLI83) in individuals with different HLA phenotypes. Immunology 1997; 92(4): 567-570.

89. Shilling HG, Young N, Guethlein LA et al. Genetic control of human NK cell repertoire. Journal of Immunology 2002; 169(I): 239-247.

90. Leung W, lyengar R, Turner $V$ et al. Determinants of antileukemia effects of allogeneic NK cells. Journal of Immunology 2004; I 72(I): 644-650.

91. Bishara A, De Santis D, Witt CC et al. The beneficial role of inhibitory KIR genes of HLA class I NK epitopes in haploidentically mismatched stem cell allografts may be masked by residual donor-alloreactive T cells causing GVHD. Tissue Antigens 2004; 63(3): 204-2I I.

92. Hsu KC, Keever-Taylor CA, Wilton A et al. Improved outcome in HLA-identical sibling hematopoietic stem cell transplantation for acute myelogenous leukemia (AML) predicted by KIR and HLA genotypes. Blood 2005; 105(I2): 4878-4884.

93. Molldrem JJ, Lee PP, Wang $C$ et al. Evidence that specific T lymphocytes may participate in the elimination of chronic myelogenous leukemia. Nature Medicine 2000; 6(9): 1018-1023.

94. Bleakley M \& Riddell SR. Molecules and mechanisms of the graft-versus-leukaemia effect. Nature Reviews Cancer 2004; 4(5): 37I-380.

95. Walter EA, Greenberg PD, Gilbert MJ et al. Reconstitution of cellular immunity against cytomegalovirus in recipients of allogeneic bone marrow by transfer of T-cell clones from the donor. The New England Journal of Medicine 1995; 333: 1038-1044.

96. Heslop HE, Smith CA, Ng C et al. Efficacy of adoptively transferred virus specific cytotoxic T lymphocytes for prophylaxis and treatment of EBV lymphoma [Abstract]. Blood 1996; 88(supplement I): 68Ia, \#2713.

97. Rossig C \& Brenner MK. Genetic modification of T lymphocytes for adoptive immunotherapy (Review). Molecular Therapy 2004; 10(I): 5-18.

98. Rosenberg SA, Yang JC \& Restifo NP. Cancer immunotherapy: moving beyond current vaccines. Nature Medicine 2004; 10(9): 909-915.

99. Hsu FJ, Caspar CB, Czerwinski D et al. Tumor-specific idiotype vaccines in the treatment of patients with B-cell lymphoma-long-term results of a clinical trial. Blood 1997; 89(9): 3129-3।35.

100. Miller RA, Maloney DG, Warnke R et al. Treatment of B-cell lymphoma with monoclonal anti-idiotype antibody. The New England Journal of Medicine 1982; 306(9): 517-522.

I0I. Coscia M, Mariani S, Battaglio S et al. Long-term follow-up of idiotype vaccination in human myeloma as a maintenance therapy after high-dose chemotherapy. Leukemia 2004; I 8(I): I39-I45.

102. Timmerman JM, Czerwinski DK, Davis TA et al. Idiotype-pulsed dendritic cell vaccination for B-cell lymphoma: clinical and immune responses in 35 patients. Blood 2002; 99(5): I5 I7- I526. 
103. Köhler G \& Milstein C. Continuous cultures of fused cells secreting antibody of predefined specificity. Nature 1975; 256(55I7): 495-497.

104. Linenberger ML, Maloney DG \& Bernstein ID. Antibody-directed therapies for hematologic malignancies (Review). Trends in Molecular Medicine 2002; 8(2): 69-76.

105. Reff ME, Carner K, Chambers KS et al. Depletion of B cells in vivo by a chimeric mouse human monoclonal antibody to CD20. Blood 1994; 83(2): 435-445.

106. Georges GE, Maris MB, Sandmaier BM et al. Nonmyeloablative unrelated donor hematopoietic cell transplantation $(\mathrm{HCT})$ for patients (pts) with poor risk, relapsed or refractory multiple myeloma [Abstract]. Blood 2004; 104 (Part I):(II)754a, \#2756.

107. Burroughs LM, Maris MB, Sandmaier BM et al. HLA-matched related (MRD) or unrelated donor (URD) non-myeloablative conditioning and hematopoietic cell transplant (HCT) for patients with advanced Hodgkin disease (HD) [Abstract]. Biology of Blood and Marrow Transplantation 2004; 10 (supplement I): (2)73-4, \#197. 